\title{
Psychomotor reminiscence as a function of sex and amount of prerest practice
}

\author{
JOAN M. DIETRICH and R. B. PAYNE \\ University of Georgia, Athens, Georgia
}

\begin{abstract}
Several studies support the hypothesis that females reminisce more than males do because they accumulate more reactive inhibition during the prerest trials. The present study explores this hypothesis further by varying the amount of continuous practice prior to a rest period of constant length. Concordant with expectations, reminiscence increased as a negatively accelerated function of prerest practice, and females reached a higher asymptotic level of reminiscence than males did. Also as expected from theory, females gained less proficiency than males did across the prerest trials.
\end{abstract}

Recent studies of psychomotor learning and performance in young adults have shown consistently that females reminisce more than males do (Coppage \& Payne, 1981; Hsu \& Payne, 1979; Huang \& Payne, 1975; Payne \& Huang, 1977; Payne \& Turkat, 1982). Although several theories of reminiscence suggest explanatory possibilities, we have found it fruitful to rationalize this sex difference in terms of Hull's (1943) concept of reactive inhibition $\left(I_{R}\right)$. According to this concept, the work of responding produces increments of negative motivation $\left(I_{R}\right)$, which accumulate with continuous practice and subside spontaneously across rest. Because $I_{R}$ opposes response tendency, the growth of task proficiency is retarded in proportion to the amount of $I_{R}$ present; but the dissipation of inhibition across rest allows proficiency to rise, thereby yielding the familiar phenomenon of reminiscence. When applied to the sex difference, the theory says that females reminisce more than males do because they generate and accumulate more $I_{R}$ during the prerest trials. And, having accumulated more, they release more across rest.

The foregoing explanation suggests several testable implications, all of which have been confirmed. For one, when the amount of continuous prerest practice was held constant while the length of the rest period was varied, both sexes reminisced as a negatively accelerated function of the amount of rest, but females reached a higher asymptotic level of reminiscence than males did and they gained less across prerest practice (McBride \& Payne, 1979). For another, when the amount of continuous practice was held constant, the contralateral transfer effect was smaller for females than for males when the transfer interval was very brief (owing to the greater burden of $I_{R}$ ); but this disadvantage lessened as the length of the transfer interval increased (Shaffer \& Payne, 1982). For a third, the well-known male superiority in continuous rotary tracking disappeared altogether

The authors' mailing address is: Department of Psychology, University of Georgia, Athens, Georgia 30602. when the length of the intertrial interval increased beyond $10 \mathrm{sec}$ (McBride \& Payne, 1980). Thus, the inhibition theory of the sex difference in reminiscence has survived a substantial amount of experimental scrutiny.

The present study provided a further test of the hypothesis that females accumulate more $I_{R}$ in prerest practice than males do. It involved an experimental arrangement in which the amount of continuous prerest practice was varied while the length of the rest period was held constant, an arrangement used in Ammons (1947) and Irion (1949). If it is assumed that there is an exponential growth of $I_{R}$ across practice, as Hull (1952) implied in his final treatment of the concept, the theory predicts (1) that reminiscence increases as a negatively accelerated function of the amount of continuous prerest practice, (2) that females reach a higher asymptotic level of reminiscence than males do and (3) that females gain less proficiency across prerest trials than males do (owing to the females' relatively greater burden of $I_{R}$ ).

\section{METHOD}

\section{Subjects}

The experimental sample consisted of 120 subjects (60 of each sex) drawn by consent from introductory psychology classes at the University of Georgia. Ages ranged from 18 to 22 years, with mean ages of 19.4 years for males and 18.9 years for females. All were of Caucasian ancestry, right-handed, and visually competent. All received course credit points for participation.

Task

The subjects were required to use mirror vision to track a small silver target as it moved clockwise at $1 \mathrm{rpm}$ through a narrow starshaped pathway. They were instructed to keep the tracking stylus on the moving target as long as possible and to avoid touching the sides of the pathway. Time on target was recorded to the nearest $.01 \mathrm{sec}$ for each unit of practice.

\section{Procedure}

The main objective of the study was the measurement of reminiscence across a rest period of constant length $(300 \mathrm{sec})$ as a function of sex and amount of continuous prerest practice (30, $60,120,240$, or $480 \mathrm{sec}$ ). As the study was originally conceived, 
the 30-sec group was thought unnecessary for the purpose of defining the early part of the prerest practice function. As sampling progressed, however, the desirability of including a 30-sec group became evident, and it was therefore added. Except for the 30sec group, the subjects of each sex were assigned without bias to the practice groups, with the constraint that each group contain 12 subjects. Although the 12 subjects of each sex in the $30-\mathrm{sec}$ group were not part of the original assignment scheme, they were drawn in the same manner from the parent population and their mean initial performance levels for $30 \mathrm{sec}$ of practice were not significantly different from those of the other groups $[F(4,110)<1]$. They were therefore regarded as equivalent subjects.

After instruction and demonstration, all subjects practiced continuously for their allotted times, rested for $300 \mathrm{sec}$, and then resumed continuous practice for $300 \mathrm{sec}$.

\section{RESULTS}

\section{Reminiscence}

As previously described, the reminiscence trends expected on theoretical grounds are shown in Figure 1. The values of the asymptotic parameters of these functions were estimated in part from previous studies (e.g., McBride \& Payne, 1979), and the values of the rate parameters were assumed to be equal for the sexes and sufficiently large to produce an early rapid rise toward asymptotic levels, as suggested by the data of Ammons (1947).

Reminiscence was quantified for subjects in the 60-, $120-, 240$-, and 480 -sec groups by taking the time-ontarget difference between the last $60 \mathrm{sec}$ of prerest practice and the first $60 \mathrm{sec}$ of postrest practice. A comparable measure was computed for each subject in the 30 $\mathrm{sec}$ group by subtracting the prerest score from the score made on the first $30 \mathrm{sec}$ of postrest practice. The mean reminiscence values for males are shown in Figure 1 as filled circles, and those for females are shown as open circles.

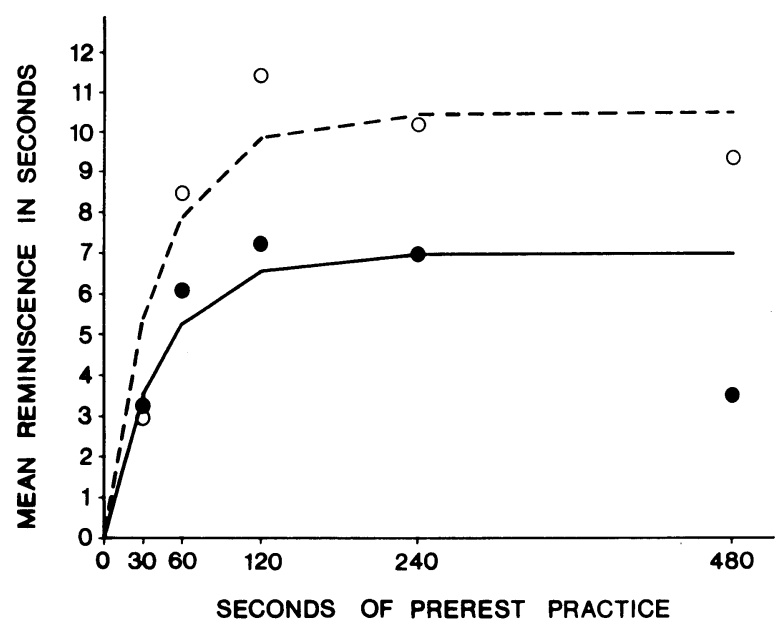

Figure 1. Reminiscence as a function of sex and amount of prerest practice. The solid and dashed curves depict theoretical functions for males and females, respectively. Obtained values for females are shown by open circles; those for males are shown by filled circles.
A variance analysis of the 120 reminiscence scores revealed that $\operatorname{sex}[\mathrm{F}(1,110)=7.44, \mathrm{p}<.01]$ and practice $[F(4,110)=3.69, p<.01]$ were significant sources of variation. The interaction of these effects was not significant $[F(4,110)<1]$. An analysis of the trend components of the practice effect, using orthogonal polynomial coefficients calculated according to Keppel (1973), showed that a second-order function provided the best description of the observed trend $[F(1,110)=$ $9.06, p<.005$ ], with no significant residual variance. A further analysis of the quadratic component by sexes provided no significant evidence of interaction. Thus, one can infer that the sexes approached their respective limits at equivalent rates.

Despite the aberrant male value in the 480-sec group, it is clear from the foregoing statistical analyses that reminiscence increased as a negatively accelerated function of the amount of prerest practice, as predicted by theory. It is also clear that females approached a higher asymptotic level than males did, but at essentially the same rate. What remains to be considered is whether the observed mean reminiscence values deviated significantly from the corresponding values of the theoretical model. Accordingly, a sum of squares for the 10 comparisons was formed, and the mean square was tested against the pooled variance of subjects treated alike. This ratio was not significant $[F(9,110)<1]$. Thus, although the theoretical curves were not necessarily the most precise descriptions of the observed trends (when compared, say, with a least squares solution), they were not significantly different from them.

\section{The "Problem" of Gain Scores}

Throughout the long history of research on psychomotor reminiscence, it has been customary to index changes in performance across rest in terms of crude gain scores. Some researchers, however, have objected to the use of crude gain scores on the grounds of the alleged modest reliability of such scores and their tendency to be somewhat negatively correlated with prerest performance levels (Manning \& DuBois, 1962). Although it may be true that unreliability in gain scores arises in part from the fact that the anchor values from which the gains are computed are themselves fallible measures, these alleged deficiencies are probably "more illusory than real" (Rogosa, Brandt, \& Zimowski, 1982, p. 735). Moreover, those who object to gain scores would probably be quite comfortable with an analysis of the anchor values, even though the information provided by such an analysis would, of necessity, be exactly the same as that provided by the gain scores.

Consider that each subject has a prerest performance score (B) and a postrest performance score (A). These two scores define what one may call the interval effect (reminiscence). The variation among the 240 scores can now be partitioned into between-subjects effects (sex, practice, interaction, and error) and within-subjects effects (interval, interactions, and error). The foregoing 
analysis revealed that practice $[\mathrm{F}(4,110)=19.52, \mathrm{p}<$ $.001]$, interval $[F(1,110)=149.68, p<.001]$, sex $x$ interval $[\mathrm{F}(1,110)=7.04, \mathrm{p}<.01]$, and practice $\mathrm{x}$ interval $[F(4,110)=3.69, p<.01]$ were all significant sources of variation. Looking first at the sex $\mathrm{x}$ interval interaction, we have the following means: Male $\bar{B}=16.02$, Male $\overline{\mathrm{A}}=21.4$, Female $\overline{\mathrm{B}}=14.25$, and Female $\overline{\mathrm{A}}=22.72$. We see that both sexes gained across the interval, but we also see that females gained more than males, that is, $(F \bar{A}-F \bar{B})>(M \bar{A}-M \bar{B})$. This difference in gains was 3.09 , and the standard deviation of the difference was 1.13 . Thus, $t(110)=2.73(p<.005$, single tail $)$. But this is simply another way of showing precisely what the analysis of reminiscence scores showed, namely, that females reminisced more than males did.

Looking next at the practice $\mathrm{x}$ interval interaction, we have the following means: $30-\sec \bar{B}=4.35,30$-sec $\overline{\mathrm{A}}=7.42,60-\mathrm{sec} \overline{\mathrm{B}}=12.41,60-\mathrm{sec} \overline{\mathrm{A}}=19.68,120-\mathrm{sec}$ $\overline{\mathrm{B}}=16.26,120-\mathrm{sec} \overline{\mathrm{A}}=25.57,240-\mathrm{sec} \overline{\mathrm{B}}=17.97,240$ $\sec \bar{A}=26.54,480-\sec \bar{B}=24.69$, and $480-\sec \bar{A}=$ 31.11 ; and the corresponding $\bar{A}-\bar{B}$ differences were $3.07,7.27,9.31,8.57$, and 6.42 . These differences, of course, are the mean reminiscence values that were examined earlier and whose trend was shown to be best described as a second-order function. Thus, we arrive at precisely the same outcome portrayed by the analysis of reminiscence scores.

\section{Prerest Practice}

If females gain more across rest than males do, and if this difference reflects a greater female accumulation of $I_{R}$ during prerest practice, it follows from $I_{R}$ theory that, as a result of the relatively greater suppression of performance potential by $I_{R}$, females should gain less proficiency than males do across the prerest trials. This implication was tested in the 120-, 240-, and 480-sec groups (the only ones in which two or more repeated measurements were available) by using the scores obtained on the first and last $60 \mathrm{sec}$ of prerest practice. The total variation among the 144 scores was partitioned into between-subjects effects (sex, group, interaction, and error) and within-subjects effects (trials, interactions, and error). The trial effect, of course, proved highly significant $[F(1,66)=40.81, p<.001]$, as did the interaction of groups and trials $[\mathrm{F}(2,66)=8.94, \mathrm{p}<$ $.001]$. This interaction is a trivial effect that merely indicates that the difference between the first and last trials increased with the amount of intervening practicehardly a surprising result.

Our primary interest, of course, was in the interaction of sex and trial effects, which turned out to be significant $[F(1,66)=8.36, p<.01]$. Looking at the simple effects, we have the following means: Male $\mathrm{T}_{1}=13.05$, Male $\mathrm{T}_{2}=20.84$, Female $\mathrm{T}_{1}=15.51$, and Female $\mathrm{T}_{2}=$ 18.44. According to hypothesis, the male difference should exceed the female difference. The value for this comparison was: $20.84-13.05-18.44+15.51=4.86$.
The standard deviation of this difference was 1.677 , and $t(66)=2.9(p<.005$, single tail). Thus, males gained more across prerest trials than females did, and the hypothesis was sustained. Because the triple interaction was not significant $[F(2,66)<1]$, the conclusion applies across all groups.

\section{DISCUSSION}

The foregoing results extend an already substantial array of evidence in support of the view that young-adult females reminisce more than males do because they accumulate more reactive inhibition during prerest practice. Quite apart from the bearing of these results upon the sex difference, they also enhance the credibility of the inhibition hypothesis per se by showing that reminiscence was best described as a negatively accelerated increasing function of the amount of prerest practice. However, lest confidence get out of hand, one should recall that previous studies of this function have suggested that reminiscence may decline somewhat when prerest practice extends beyond about $8 \mathrm{~min}$ (Ammons, 1947; Irion, 1949). Whether the observed falloff was a significant departure from expectation one cannot say, for no trend analyses were performed and no test of the simple effect was provided.

With regard again to the sex difference, what remains to be considered is the question of why young-adult females accumulate more $I_{R}$ than males do. The current approach to this question focuses on the relationship between reminiscence and certain phases of the menstrual cycle, with particular reference to systematic fluctuations in the levels of estrogenic hormones. Attention was first drawn to the estrogenic components of the cycle by studies of prepubescent children; in these studies, males reminisced slightly, but significantly, more than females, contrary to the findings in young adults (Horn, 1975; Zegiob \& Payne, 1977). An obvious implication was that the inversion of sex dominance in reminiscence might be related to the changes in hormonal production and distribution that define the onset of puberty. Following a review of evidence for the adrenergic properties of estrogenic hormones, Wells and Payne (1979) proposed and tested an "activation" hypothesis that said, in effect, that peak estrogen levels should induce more vigorous responding than nadir levels should, and that this in turn should generate more reactive inhibition as defined by Hull (1943). It follows from this that one should find more reminiscence when subjects are tested on or nearby the ovulatory day of the cycle than when they are tested during the menstrual or early proliferative days. The expected findings were indeed realized by Wells and Payne, and they were replicated in almost exact detail by LamsonMcBride and Payne (1981).

Current exploration of the "activation" hypothesis involves an experimental design that not only replicates the design of the previous studies but adds contraceptively medicated subgroups tested on comparable days of the cycle. Given the known suppressive effects of contraceptive medication upon follicular growth and estrogen secretion, the hypothesis predicts that the medicated subjects will exhibit relatively low and constant magnitudes of reminiscence across cycle phases. As sampling approaches completion, it is already clear that previous results will be replicated once again and that medication effects will conform to expectation (Quante, Brown, \& Payne, Note 1). The relevance of such findings to the sex difference in reminiscence in unselected samples lies simply in the fact that, given the more or less elevated estrogen levels across about $70 \%$ of the average menstrual cycle, the probability is about 0.7 of sampling a subject in that condition without reference to cycle data. This would, of course, impose a statistical bias in favor of greater female reminiscence. 


\section{REFERENCE NOTE}

1. Quante, A. L., Brown, I. S., \& Payne, R. B. Hormonal regulation of psychomotor reminiscence in females. Paper presented at the annual meeting of the Southern Society for Philosophy and Psychology, Atlanta, March 1983.

\section{REFERENCES}

Ammons, R. B. Acquisition of motor skill: II. Rotary pursuit performance with continuous practice before and after a single rest. Journal of Experimental Psychology, 1947, 37, 393-411.

Coppage, S. J., \& PAYne, R. B. An experimental test of current theories of psychomotor reminiscence. Perceptual and Motor Skills, 1981, 52, 343-352.

Horn, P. W. Pursuit rotor speed, sex differences, and reminiscence in young children. Journal of Psychology, 1975, 91, 81-85.

Hsu, S. H., \& PAYNe, R. B. Effector localization and transfer of reactive inhibition. Journal of Motor Behavior, 1979, 11, 153-158.

Huang, K. L., \& Payne, R. B. Individual and sex differences in reminiscence. Memory \& Cognition, 1975, 3, 252-256.

Hull, C. L. Principles of behavior. New York: Appleton-CenturyCrofts, 1943.

Hull, C. L. A behavior system. New Haven: Yale University Press, 1952.

Irion, A. L. Reminiscence in pursuit-rotor learning as a function of length of rest and of amount of pre-rest practice. Journal of Experimental Psychology, 1949, 39, 492-499.

KE PPEL, G. Design and analysis: $A$ researcher's handbook. Englewood Cliffs, N.J: Prentice-Hall, 1973.
Lamson-McBride, E., \& Payne, R. B. Psychomotor reminiscence and the menstrual cycle. Bulletin of the Psychonomic Society, 1981, 17, 97-100.

Manning, W. H., \& DuBois, P. H. Correlational methods in research on human learning. Perceptual and Motor Skills, 1962, 15, 287-321.

McBride, D. K., \& Payne, R. B. Psychomotor reminiscence as a function of sex and length of rest period. Journal of Motor Behavior, 1979, 11, 59-64.

McBride, D. K., \& PAYne, R. B. The sex difference in rotary pursuit performance: Aptitude or inhibition? Journal of Motor Behavior, 1980, 12, 270-280.

Payne, R. B., \& Huang, K. L. Interaction of sex and task differences in reminiscence. Journal of Motor Behavior, 1977, 9, 29-32.

Payne, R. B., \& Turkat, I. D. Sex, race, and psychomotor reminiscence. Bulletin of the Psychonomic Society, 1982, 19, 336-338.

Rogosa, D., BrandT, D., \& Zimowski, M. A growth curve approach to the measurement of change. Psychological Bulletin, 1982, 92, 726-748.

Shaffer, G. S., \& PAyne, R. B. Contralateral transfer of reactive inhibition as a function of sex and interpolated rest. Perceptual and Motor Skills, 1982, 54, 979-985.

Wells, K. C., \& PAyne, R. B. Psychomotor reminiscence as a function of gonadal steroid hormone variation. Bulletin of the Psychonomic Society, 1979, 14, 197-200.

Zegiob, L., \& PAyne, R. B. Reminiscence in children as a function of sex. Bulletin of the Psychonomic Society, 1977, 9, 173-175.

(Manuscript received for publication May 23, 1983.) 